CDD: 152.4

\title{
Nussbaum on the cognitive nature of emotions
}

\section{Gustavo Ortiz Millán}

Universidad Nacional Autónoma de México

Instituto de Investigaciones Filosóficas

Circuito Mario de la Cueva s/ $n$

Ciudad Universitaria

Ciudad de México 04510, Mexico

gmom@filosoficas.unam.mx

Received: 14.07.2016; Accepted: 15.08.2016

DOI: http://dx.doi.org/10.1590/0100-6045.2016.V39N2.GOM

\begin{abstract}
Martha Nussbaum tells us that emotions are cognitive value judgments. She claims that her theory, the neo-Stoic theory of emotions, can handle traditional objections to cognitive theories of emotions. However, in this paper I hold that she improperly takes advantage of the ambiguity of the term "cognition": she faces the problems that arise when the term "cognition" is used in a very narrow sense (which claims that emotions are beliefs), resorting to a very wide sense under which any mental process is cognitive. I argue that this move does not solve the problems of the traditional cognitive theories of emotions. In order to show this, I distinguish four senses in which the term "cognitive" is used in theories of emotions, I analyze the ways Nussbaum uses them and why this move does not solve the traditional objections.
\end{abstract}

Keywords: Nussbaum. Value judgments. Cognition. Emotions. Neo-Stoicism

1. Martha Nussbaum tells us that emotions are "intelligent responses to the perception of value" (Nussbaum 2001, p. 1). Emotions are value judgments, she claims, and these judgments must be understood as some kind of cognitive states that allow us to discover values and reasons in the world. Our value judgments, and hence emotions, are a type of beliefs, so they may be either true or false. This is the cognitive-evaluative view of emotions. 
Nussbaum's view is a variation of the traditional cognitive theory of emotions: emotions are judgments of value that are intentional states or, more precisely, propositional attitudes. Emotions are specified in terms of propositions. You are resentful with someone when you believe that person has intentionally wronged you. Cognitivism claims that this feature is essential to emotions: in order to have an emotion, one must have some kind of attitude directed at a proposition, and not just any kind of attitude, but more precisely some form of belief. Emotions are evaluative beliefs. When you are resentful with someone, your resentment consists in negative beliefs about that person's action towards you.

This point of view is not new, it goes back at least to the Stoics. They claimed that emotions are judgments, and that these are propositional. However, this view has been subjected to the objection — originally raised by Posidonius against Chrysippus ${ }^{1}$ — that a cognitive account cannot explain the emotions of animals and pre-linguistic babies, since they are not capable of the linguistic capacities needed for propositional thought. The ancient Stoics simply denied that these creatures had any emotions, since they conceived emotions as identified with judgments or affirmations of propositions. But since many people would not be so willing to deny emotions to animals and babies, this has been a constant objection to the traditional cognitivist theory. ${ }^{2}$ Nussbaum agrees that this is a problem for traditional cognitive views: "Cognitive views that leave out infancy cannot explain the way in which the emotions of adult life bear the shadows of earlier objects" (Nussbaum 2001, p. 230). However, she claims that her version of cognitivism can handle this objection. She calls this new version of the cognitivist theory a "neo-Stoic" account of emotions. Nussbaum faces the objection by switching from a very narrow meaning of the term "cognitive" to a broader one so that it applies to the emotions of animals and pre-linguistic babies, and then show how even these emotions are cognitive. She defends traditional versions of the theory that claim that

${ }^{1}$ Posidonius criticized Chrysippus' intellectualism and he wanted the Stoics to go back to Plato's tripartite soul and acknowledge that emotions cannot be purely rational. Cfr. Sorabji 2002: ch. 1; see also Wringe 2011.

${ }^{2}$ For more on this debate, see Deigh 1994. 
emotions are propositional attitudes resorting to cognitive science and arguing that this cognitive approach explains how animals and babies have emotions.

My contention is that Nussbaum improperly takes advantage of the ambiguity of the term "cognition": this ambiguity allows us to say quite different things when we talk about the cognitive nature of emotions. She defends traditional cognitive theories, which use the term "cognitive" in a very specific and narrow way, by switching to a very broad sense of the term, one defended by contemporary cognitive sciences. These two uses of the term "cognition" are very different, but it is possible to defend the first use of the term with the second because this last one is so broad that almost any claim about the cognitive nature of mental states can be defended by it. But then we are talking about something different. Cognitive scientists, such as the ones Nussbaum refers to, would hardly commit themselves to the very specific use of the term "cognitive" in which emotions are evaluative beliefs. I will distinguish four senses of the term "cognitive" to show that this move is not allowed to Nussbaum - there may be more senses of this term, but these four serve my purpose. ${ }^{3}$ Of course some states may be cognitive in more than one sense, but this does not affect my point in this paper.

2. In discussions about the nature of emotions - as well as in many other debates - the term "cognitive" has at least four different senses. Here, I am going to proceed from the wider to the narrower sense. First, there is one that involves the findings of cognitive science, primarily based on empirical research of the brain and of mental processes. In cognitive psychology, for instance, the term refers to an information processing view of an individual's psychological functions (perceiving, thinking, remembering, understanding language, learning and other mental phenomena). Neil Stillings et al., for instance, define the word in this way:

The word cognitive refers to perceiving and knowing. Thus, cognitive science is the science of the mind. [...] Cognitive scientists view the human mind as a complex system that receives, stores, retrieves,

${ }^{3}$ Agnes Moors (2007), for instance, distinguishes eight different senses of the term "cognitive". 
transforms, and transmits information. These operations on information are called computations or information processes, and the view of the mind is called the computational or information-processing view. (STILLINGS et al. 1995, p. 1)

Emotions are cognitive under this sense given that they are pieces of the information that we process when we think - not only emotions, but also conative states such as desires are cognitive under this interpretation. Any mental process is cognitive under this sense of the word. In this case, the term does not refer to any particular kind of mental state, but to the mental activity of thinking or information processing. Also, in the same sense, wider interpretations of the meaning of "cognition" link it to the development of concepts. This sense I will call "cognitive ${ }_{1 .}$ "

The second sense of the term is narrower: by "cognitive," a number of philosophers have understood the program in which emotional phenomena may be dealt, primarily, in terms of the intentional states that figure in commonsense psychology. This theory was first proposed, in these terms, to oppose feeling and physiological theories of emotions. According to the latter, emotions are something we feel inside us (for instance, the pangs of despised love or the visceral character of anger), and feelings can be viewed as introspective experiences that arise physiologically in the brain or in the body. An emotion, the physiological theories claimed, is primarily defined by the quality and the intensity of the sensation, rather than by its intentional character. The pleasantness or unpleasantness of emotions is what causes people to act in ways peculiar to the emotion. So defined, emotions were beyond any kind of rational constraint. On the other hand, the theorist of intentionality thinks that the sensation and physiological theories are wrong because they see emotions just as feelings arising from our physiology, or as mere causal forces, leaving aside the intentional nature of emotions. Emotions are intentional, they stress, and this means that they are directed towards objects, actions or states of affairs in the world, and these are the ones that explain the emotions. This usually means that they are attitudes towards certain propositions, that their content is conceptual and that they are not immune to rational criticism. However, with the use of the term by these theories, as Paul Griffiths (1997, p. 2) says, "the label 'cognitive' suggests a concern with the findings of cognitive psychology and with the study of emotions as part of human information processing and nothing could be more misleading". 
Griffiths proposes, in the case of these theories, to call them "propositionalattitude theories," rather than "cognitive theories." We can call this propositional attitude approach "cognitive."

Some people call this last approach "intentionalism," however, "propositional attitude" should not be taken as tantamount to "intentional," since the former implies that these attitudes have a propositional or linguistic content, that is, that their content is always conceptual, whereas the latter leaves open the possibility that the intentional content of a mental state be nonconceptual. Intentionality, at least in some cases, may be a two-level phenomenon: one involving judgment, and a second level involving nonconceptual content. This may be relevant in the case of emotions, since even though they are intentional, they may also include representations that are nonconceptual, and this is why they fail to exhibit full logical complexity. ${ }^{4}$ We can then call this sense "cognitive 3. ." It is cognitive, because even though it includes an element of non-conceptual representation, i.e., something that is not captured in linguistic terms, it does include the intentional character of cognitive $_{2}$ states. It may be useful to distinguish this sense in discussions about the intentional character of emotions, even though it is not a sense that plays any role in Nussbaum's theory - even though she suggests that an emotion may involve an experience so rich that "a propositional view would not capture," she explicitly rejects "the presence of the noncognitive" (Nussbaum 2001, pp. 64-65). She would rather side with the propositional attitude theorist, since the neo-Stoic theory holds that the content of emotions is fully cognitive and propositional.

Fourth, "cognitive" refers to knowledge, and in this sense belief would be the paradigmatic cognitive state. Cognitive theories of emotions, viewed in this way, hold that emotions are forms of beliefs about the world and are able to be true or false and, in its cognitive-evaluative version, provide us with knowledge of reasons and values. ${ }^{5}$ This meaning of the term, "cognitive 4 ," is

${ }^{4}$ Cfr. Gunther 2003b, and the essays collected in Gunther 2003a.

${ }^{5}$ This is the way "cognitive" is used, for instance, in discussions about cognitivism and non-cognitivism in moral psychology: cognitivists claim that value judgments are belieflike states, apt to be true, and non-cognitivists deny this claim, conceiving these judgments as states with no truth values. See McNaughton 1988.

Manuscrito - Rev. Int. Fil., Campinas, v.39, n.2, pp. 119-131, abr.-jun. 2016. 
not unrelated to the first two senses of the term "cognitive"; it is actually compatible with them (it may not be fully compatible with the third sense, since the non-cognitive character of emotions may be beyond propositional knowledge). Belief and knowledge are also paradigmatic cases of propositional attitudes or intentional states, and the quintessential informational states that we process when we think. However, there is no commitment from the two other theories to see emotions (or other mental states, for that matter) in this way, because while their understanding of the term "cognitive" is broad (more in the first than in the second sense), the use of the term by this third theory is rather narrow. For example, emotions may be cognitive in any of the first two senses, but not cognitive in the fourth; they may be cognitive in the sense that they are part of our thinking processes, but not in the sense that they are beliefs and have truth-values.

It is under this fourth meaning, for example, that the distinction cognitive/conative makes more sense. Understood in the first two senses, the distinction is blurred. Conative states, such as desires or intentions, are pieces of information processes just as beliefs are; also, they are propositional and intentional just as beliefs. But, unlike "cognitive," or "belief," "conative" refers to the deliberate, goal-oriented, or striving component of motivation, the proactive aspect of behavior. Conative states work as motivating forces that

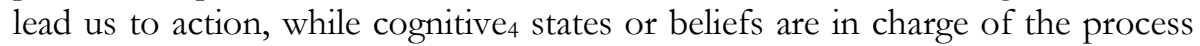
of knowledge acquisition, and provide no motivation by themselves - so says the Humean, at least.

To summarize, we can identify at least four different meanings of the term "cognitive":

\begin{tabular}{|c|c|}
\hline & Meaning \\
\hline Cognitive $_{1}$ & $\begin{array}{c}\text { "Cognitive" refers to the information processing } \\
\text { view of an individual's psychological functions } \\
\text { (perceiving, thinking, remembering, } \\
\text { understanding language, learning and other } \\
\text { mental phenomena). This is the way it is used in } \\
\text { cognitive sciences. }\end{array}$ \\
\hline
\end{tabular}




\begin{tabular}{|c|c|}
\hline Cognitive $_{2}$ & $\begin{array}{c}\text { "Cognitive" refers to propositional attitudes, } \\
\text { such as beliefs, but also desires. Sometimes also } \\
\text { called "intentionalism". }\end{array}$ \\
\hline Cognitive $_{3}$ & $\begin{array}{c}\text { "Cognitive" refers also to intentional states, but } \\
\text { "intentionality" is, at least in some cases, a two- } \\
\text { level phenomenon: one involving judgment, and } \\
\text { a second level involving non-conceptual } \\
\text { content. }\end{array}$ \\
\hline Cognitive $_{4}$ & "Cognitive" refers to belief and knowledge. \\
\hline
\end{tabular}

3. "Cognition," therefore, is an ambiguous word used in very different ways. My contention is that Nussbaum improperly takes advantage of this ambiguity to defend her cognitive-evaluative theory. Her understanding of the term wanders around the four different senses of "cognitive" that I have presented here. When defining the term, at the beginning of her Upheavals of Thought, she claims: "By 'cognitive' I mean nothing more than 'concerned with receiving and processing information.' I do not mean to imply the presence of elaborate calculation, of computation, or even of reflexive self-awareness" (Nussbaum 2001, p. 23). In a later paper, she claims: "By 'cognitive' processes I mean processes that deliver information (whether reliable or not) about the world; thus, I include not only thinking, but also perception and certain sorts of imagination" (Nussbaum 2004, p. 198). "Receiving and processing information" or "processes that deliver information" are uses of the term that no cognitive scientist would object to. So she uses the term "cognitive" in the first sense that I have identified here.

Then she goes on to use the term in the second sense, meaning intentional, and opposing sensation or physiological theories: "Although I believe that emotions are, like other mental processes, bodily, I also believe [...] that seeing them as in every case taking place in a living body does not give us reason to reduce their intentional/cognitive components to nonintentional bodily movements" (Nussbaum 2001, p. 25). Emotions, she claims, are cognitive in the sense that they are intentional; emotions

are about something: they have an object [...] The object [of an emotion] is an intentional object: that is, it figures in the emotion as it is seen or 
interpreted by the person whose emotion it is. Emotions are not about their objects merely in the sense of being pointed at them and let go, the way an arrow is let go against its target. Their aboutness is more internal and embodies a way of seeing. (NUSSBAUM 2004, p. 188)

A way of seeing is characteristic of intentional states, they always represent the perspective of the agent. Now, emotions are not only cognitive in the sense that they are intentional, but they are also propositional attitudes. Nussbaum claims that an emotion "is identical with the acceptance of a proposition that is both evaluative and eudemonistic" (Nussbaum 2004, p. 193); even when she acknowledges that an emotional experience usually contains more than merely that propositional content:

It contains rich and dense perceptions of the object, which are highly concrete and replete with detail. Thus, typically grief is not just an abstract judgment plus an ineliminable localizing element: it is very richly particular. Even if its propositional content is, "My wonderful mother is dead," the experience itself involves a storm of memories and concrete perceptions that swarm around that content, but add more than is present in it. The experience of emotion is, then, cognitively laden, or dense, in a way that a propositional-attitude view would not capture. (Nussbaum 2001, p. 65)

But whatever is not captured by this view is, anyhow, cognitively 1 laden, by the storm of memories and perceptions involved - as I said before, she is not making any concessions "to the presence of the noncognitive", that is, to any kind of non-conceptual content as the one cognitive 3 theories talk about (Nussbaum 2001, p. 64). So everything remains in the realm of the cognitive, even those experiences that are not captured by the propositional content of an emotion.

Finally, she also uses the term "cognition" in the fourth sense, meaning, quite literally, a truth-bearing state, a belief:

I have spoken of truth. And it is, of course, a consequence of the view I have been developing that emotions, like other beliefs, can be true or false, and (an independent point) justified or unjustified, reasonable or unreasonable. The fact of having an emotion depends on what the person's beliefs are, not on whether they are true or false. So if I believe 
my mother to be dead and grieve, and she is not really dead, my emotion is in that sense false. (NUSSBAUM 2001, p. 46)

The important point here is that emotions, "like other beliefs," have truth-values: love, anger or jealousy, may be, quite literally, true or false, just as other beliefs are. This is what she ultimately aims to defend when claiming that emotions are evaluative beliefs.

Playing with the different senses of the term "cognition," Nussbaum is able to defend her theory from the usual objections to cognitivism. She faces objections that are raised against the view that emotions are propositional attitudes or evaluative beliefs, turning to $\operatorname{cognition}_{1}$, that is, to cognitive psychology and neurological work on emotion. This is the way in which she faces the objection that claims that one can have an emotion without cognitive or evaluative attitudes, that is, that non-cognitive content may give rise to an emotion. Robert Zajonc, for instance, denies $\operatorname{cog}$ nitivism 4 (and intentionalism, i.e., cognitivism 2 ) by showing that affective reactions can be induced without involving beliefs; certain stimuli, with no beliefs attached, can give rise to emotional reactions. He argued that affective and cognitive systems are independent, and that affect may come first in generating emotions. ${ }^{6}$ Another related objection, as I have already mentioned, claims that $\operatorname{cognitivism}_{4}$ is unable to account for the emotions of animals and pre-linguistic babies. Nussbaum says that her new version of the cognitive theory of emotions, neoStoicism, is able to answer these objections. If Zajonc's objections are that emotions cannot be reduced to cognitive states, since they involve noncognitive, affective states, then Nussbaum's answer is that Zajonc "simply uses different terminology", and that when he talks about feelings and affects, it is actually about intentionality that he is talking about.

Once we discover that intentionality plays a significant role even in his account, we may conclude, I think, that insofar as there is a coherent account present in Zajonc, it is at any rate not one that actually upsets the main contentions of the intentionalists. He seems to be animated by the thought that the intentionalist view cannot make any room for

${ }^{6}$ See Zajonc, 1980; 1984 and 2000.

Manuscrito - Rev. Int. Fill, Campinas, v.39, n.2, pp. 119-131, abr.-jun. 2016. 
feeling of any kind, or for the fact that emotions register in awareness. Since that is obviously not the case with [intentionalists such as] Lazarus, Ortony, and Oatley, we may conclude that misunderstanding animates this debate. Zajonc's view does remind us, however, that we need to develop a flexible account of intentionality and cognition that does not focus exclusively on language. (NUSSBAUM 2001, p. 113)

So when we realize, we are told, that the whole discussion between Zajonc and the cognitivists 4 is based on a terminological confusion, we will see that the non-cognitive affective states that he claims give rise to emotions are actually intentional and cognitive, we just have to develop a more flexible account of these terms, an account of intentionality and cognition that does not focus exclusively on beliefs. If we proceed in this way, we are going to be able to account for the emotions of animals and pre-linguistic babies, whose emotions are apparently based on non-cognitive affective states — but if we develop a more flexible account of intentionality and cognition that does not focus exclusively on language, then we will see that even their emotions are cognitive.

While Zajonc's objection is that we cannot reduce emotions to cognitive $_{4}$ states, given that there are non-cognitive affective states that do not allow this reduction, Nussbaum answers that even these latter states can be seen as cognitive and intentional, just by developing a more flexible account of cognition and intentionality. Evidently, Zajonc would reject this move; to be sure, that is not the meaning of the term "cognition" that he is using and he would reject Nussbaum's move, most likely he would insist that his objection stands still. Zajonc criticized the psychologist Richard Lazarus for improperly broadening the definition of "cognitive appraisal", and I think very similar words can be applied to Nussbaum:

His argument is based entirely on an arbitrary definition of emotion that requires cognitive appraisal as a necessary precondition. To satisfy this concept of emotion Lazarus has broadened the definition of cognitive appraisal to include even the most primitive forms of sensory excitation, 
thus obliterating all distinction between cognition, sensation, and perception. (ZAJONC 1984, p. 117) ${ }^{7}$

Something similar could be said of Nussbaum: to defend her concept of emotion as a cognitive 4 state, she has broadened the definition of "cognitive" to include affects, feelings and the kinds of non-cognitive 4 states that gave so much trouble to previous cognitivists, and with this move she claims that she has defended the cognitive 4 theory that claims that emotions are beliefs and give us knowledge.

The problem with Nussbaum's theory is that she tries to defend a very specific sense of the term "cognitive," in which emotions are evaluative beliefs and propositional attitudes, resorting to a much wider sense of "cognitive," in which even non-cognitive 4 states such as Zajonc's affects and feelings, can be seen as cognitive. But this sense does not imply that emotions are propositional attitudes or belief-like states, that is, the theory that most critics of cognitivism 2 and cognitivism $_{4}$ object — from Posidonius to Zajonc. Nussbaum is not allowed to make this move given the specificity of the cognitive theory she favours. The thesis that she ultimately wants to defend, namely, that emotions are some form of evaluative beliefs and that can give us knowledge, cannot be defended resorting to the first, or even the second, senses of the term "cognition." Not the first, since emotions, understood cognitively1, are just thought processes that do not necessarily have truth-values. If we were to understand other mental states in this way, then this would result in a very peculiar theory where any kind of state, such as desires or even sensations would have truth-values. The reasons for resisting the use of cognitive 2 to defend her neo-Stoic theory are very similar: not all propositional attitudes, and certainly not all intentional states (say, conative states) have truth-values (although some other philosophers, not Nussbaum - insofar as I know have argued in favour of this kind of "desire-as-belief" thesis in which desires have truth values). Thus, Nussbaum is not allowed to broaden the definition of "cognitive" as she does to defend her neo-Stoic theory; her theory is still prey

7 Zajonc is criticizing Lazarus general view, but in particular it is an answer to Lazarus 1984. 
to the same objections that haunt traditional Stoic and cognitive 4 theories of emotions. ${ }^{8}$

\section{References}

DeIGH, J. "Cognitivism in the Theory of Emotions". Ethics vol. 104, pp. 824854, 1994.

Griffiths, P. What Emotions Really Are. Chicago: The University of Chicago Press, 1997.

Gunther, Y. (ed.). Essays on Non-Conceptual Content, Cambridge, Mass.: The MIT Press, 2003a.

“Emotion and Force”. In: Gunther (ed.) (2003), pp. 279-288.

Lazarus, R. "On the Primacy of Cognition". American Psychologist vol. 39, pp. 124-129, 1984.

MCNAughton, D. Moral Vision. Oxford: Blackwell, 1988.

Moors, A. "Can Cognitive Methods be used to Study the Unique Aspect of Emotion: An Appraisal Theorist's Answer". Cognition and Emotion vol. 21, pp. 1238-1269, 2007.

Nussbaum, M. "Emotions as Judgments of Value and Importance". In: Solomon (2004), pp. 183-199.

- Upheavals of Thought: The Intelligence of Emotions. New York: Cambridge University Press, 2001.

Solomon, R. (ed.), Thinking about Feeling, Oxford: Oxford University Press, 2004.

SORABJI, R. Emotion and Peace of Mind: From Stoic Agitation to Christian Temptation. Oxford: Oxford University Press, 2002.

8 Research for this paper was made possible by a grant provided by the Dirección General de Asuntos del Personal Académico of UNAM. 
Stillings, N.A., Weisler, S.E., Chase, C.H., Feinstein, M.H., GARField, J.L., Rissland, E.L. Cognitive Science. $2^{\text {nd }}$ ed. Cambridge, Mass.: The MIT Press, 1995.

Wringe, B. "Posidonius on Emotions and Non-Conceptual Content". Prolegomena vol. 10, pp. 185-213, 2011.

Zajonc, R. "Feeling and Thinking: Closing the Debate on the Primacy of Affect". In: J. FORGAS (ed.), Feeling and Thinking. Cambridge: Cambridge University Press, 2000, pp. 31-58.

- "Feeling and Thinking: Preferences Need no Inferences". American Psychologist vol. 35, pp. 151-175, 1980.

" "On the Primacy of Affect". American Psychologist vol. 39, pp. 117-123, 1984.

Manuscrito - Rev. Int. Fil., Campinas, v.39, n.2, pp. 119-131, abr.-jun. 2016. 